Supporting Information for:

\title{
Confined, Templated and Break-Through Crystallization Modes in Poly(3-dodecylthiophene)-block-Poly(ethyl methacrylate) Block
}

\section{Copolymers}

Jin-Seong Kim广, Young Jun Lee ${ }^{\dagger}$, Jonathan P. Coote", Gila E. Stein*,\# and Bumjoon J. Kim*,广

$\dagger$ Department of Chemical and Biomolecular Engineering, Korea Advanced Institute of Science and Technology (KAIST), Daejeon 34141, Korea

\# Department of Chemical and Biomolecular Engineering, University of Tennessee, Knoxville, Tennessee 37996, United States

*E-mail: bumjoonkim@kaist.ac.kr,gstein4@utk.edu 
Supplementary Figures

CTR

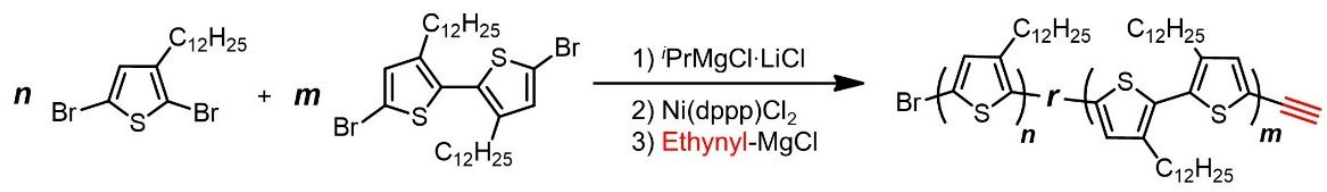

RR controlled P3DDT-alkyne

RAFT Polymerization

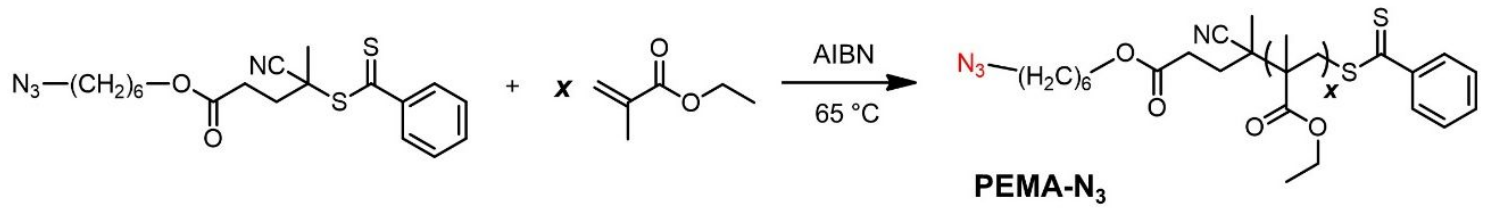

Click Chemistry
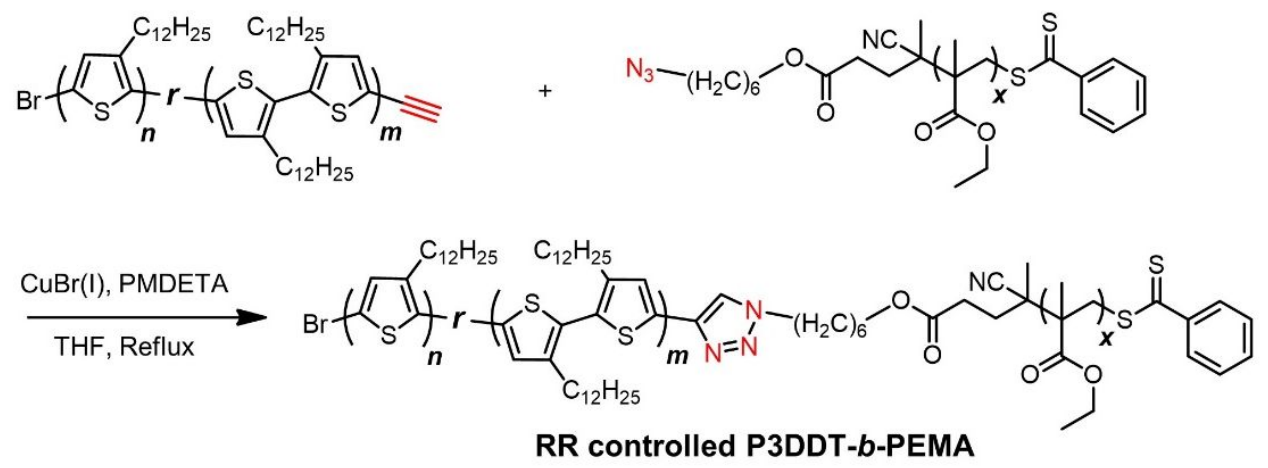

Scheme S1. Synthetic route for RR-controlled P3DDT- $b$-PEMA copolymers using CTP and "click" reaction. 


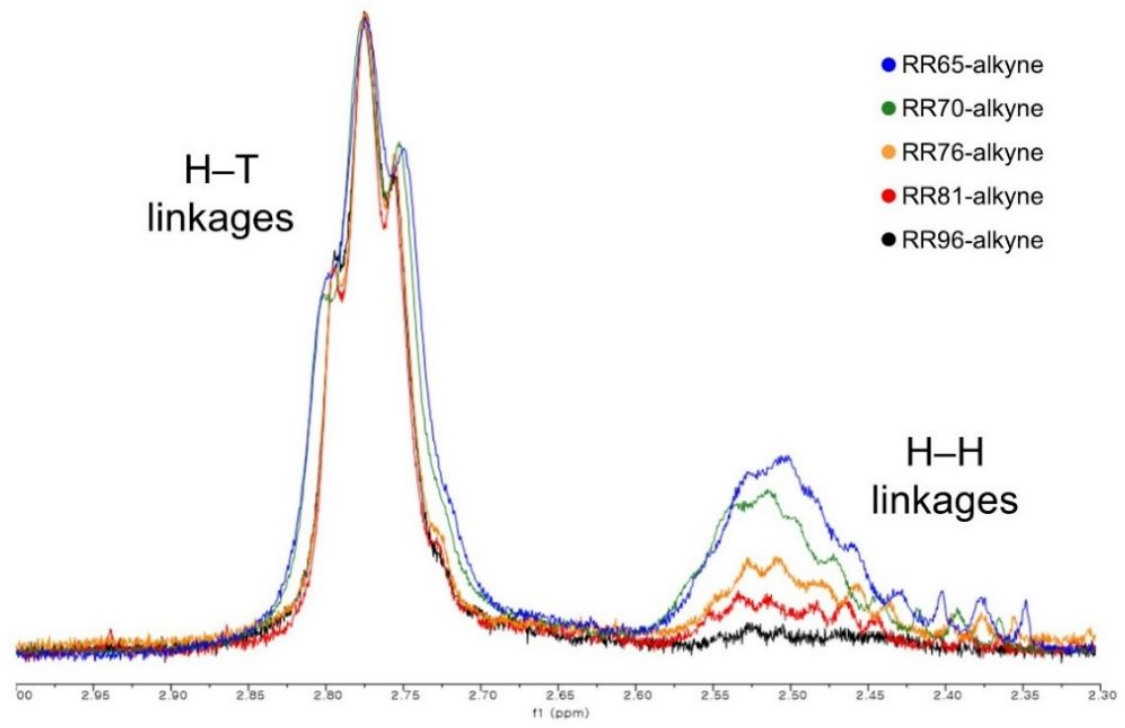

Figure S1. Normalized ${ }^{1} \mathrm{H}$ NMR spectra from $\delta 2.30$ to 3.00 for a series of RR controlled P3DDT-alkynes. 

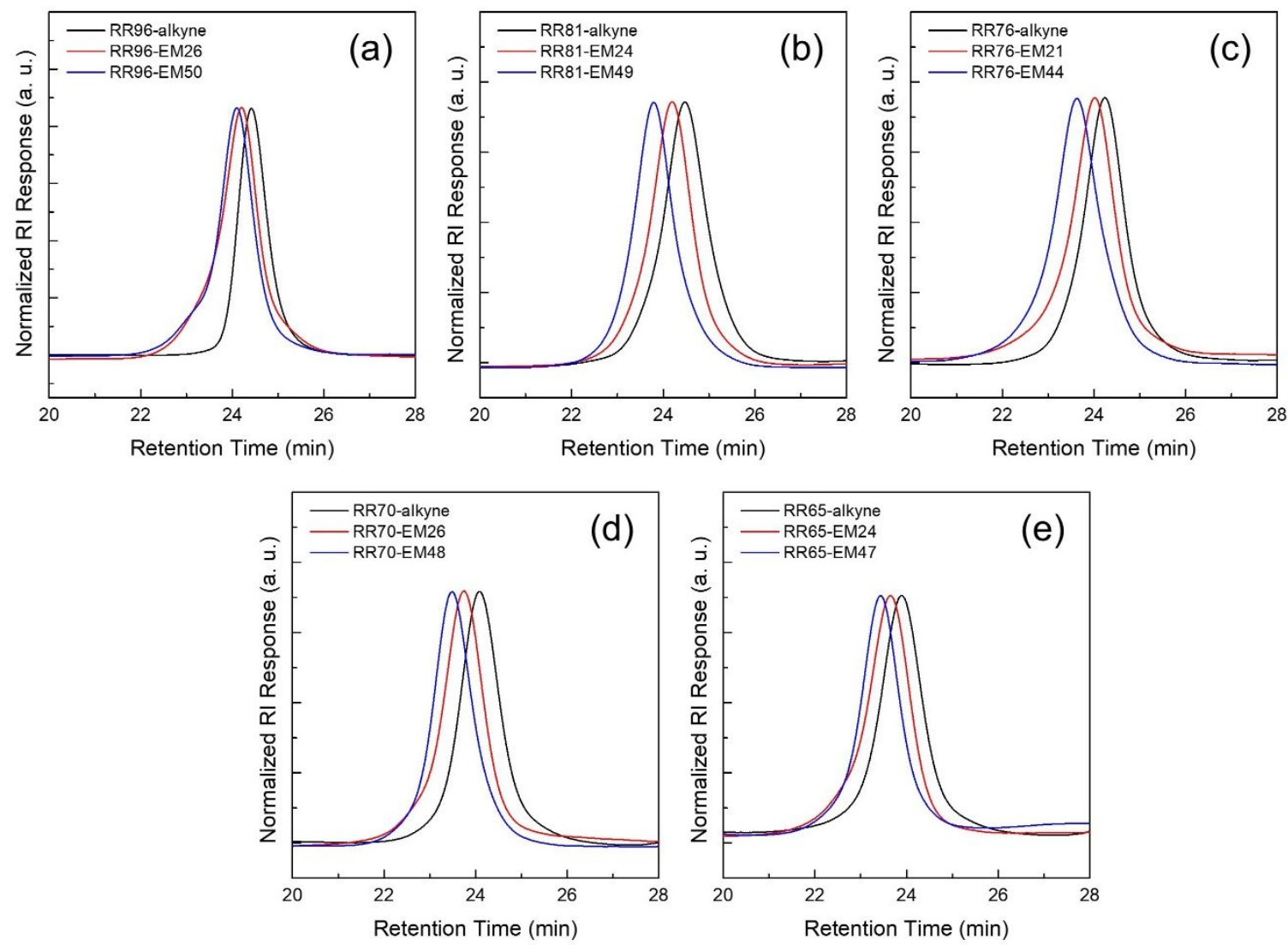

Figure S2. SEC traces of BCPs derived from (a) RR 96-alkyne, (b) RR 81-alkyne, (c) RR76alkyne, (d) RR70-alkyne and (e) RR65-alkyne. The SEC was performed with THF at a flow rate of $1 \mathrm{~mL} \mathrm{~min}{ }^{-1}$. The figure shows peak shift toward higher molecular weight with a monomodal distribution. 


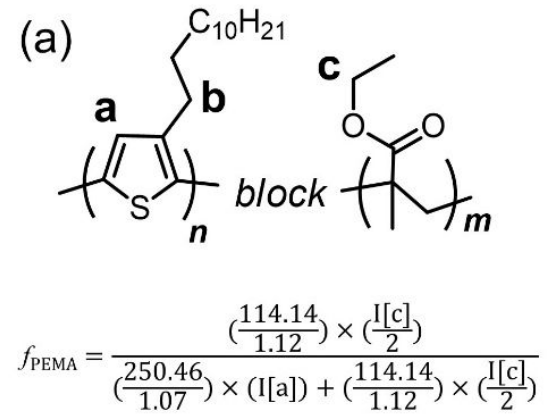

${ }^{*} \mathrm{I}[x]=$ integration of peak $X$

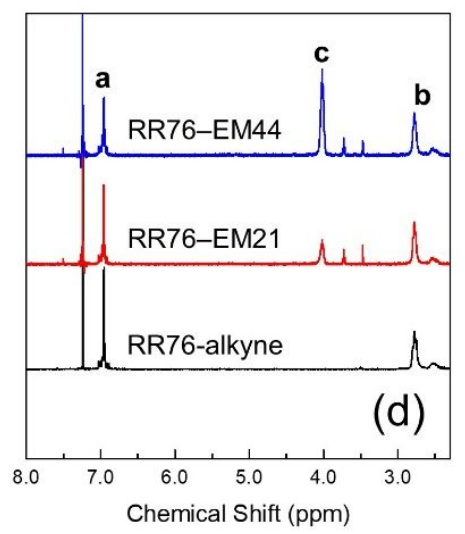

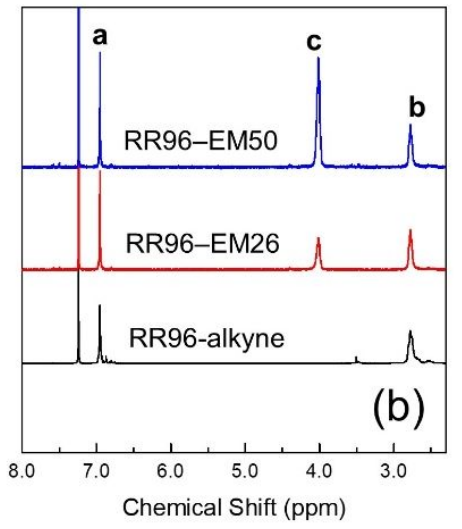
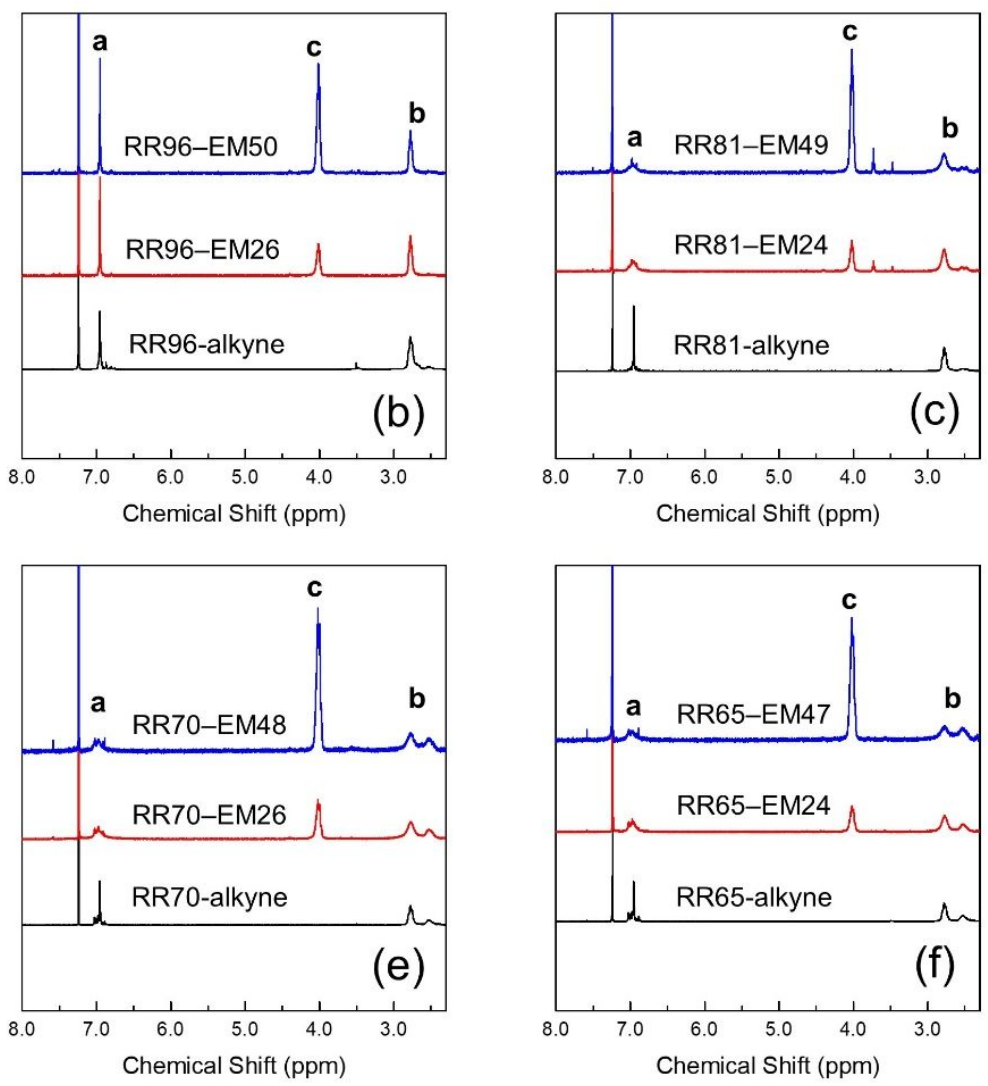

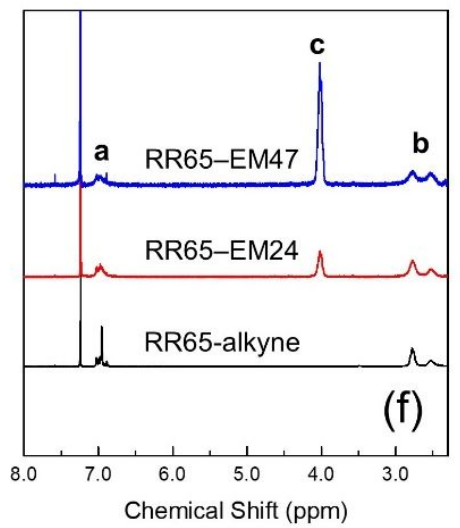

Figure S3. (a) The $f_{\text {PEMA }}$ values of all the P3DDT- $b$-PEMA copolymer were calculated using the equation described in this Figure. The density $(\rho)$ of the polymers: $\rho_{\text {P3DDT }}=1.07 \mathrm{~g} \mathrm{~cm}^{-3}$, $\rho_{\text {PEMA }}=1.12 \mathrm{~g} \mathrm{~cm}^{-3} \cdot{ }^{1-2}{ }^{1} \mathrm{H}$ NMR spectra from $\delta 2.30$ to 8.00 of P3DDT- $b$-PEMA copolymers that have (b) RR 96, (c) RR 81, (d) RR 76, (e) RR 70 and (f) RR 65\% P3DDT blocks. 
(a) $2^{\text {nd }}$ Heating

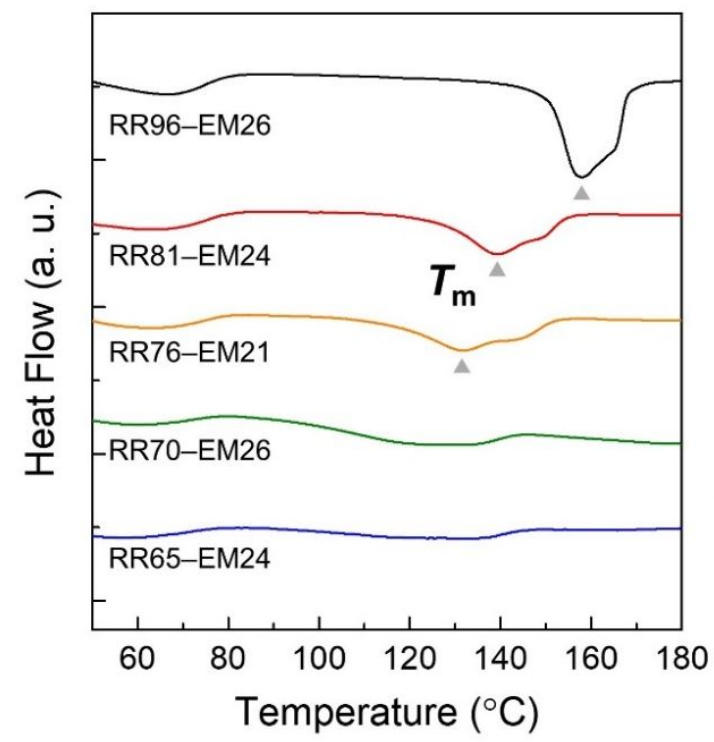

(b) $2^{\text {nd }}$ Cooling

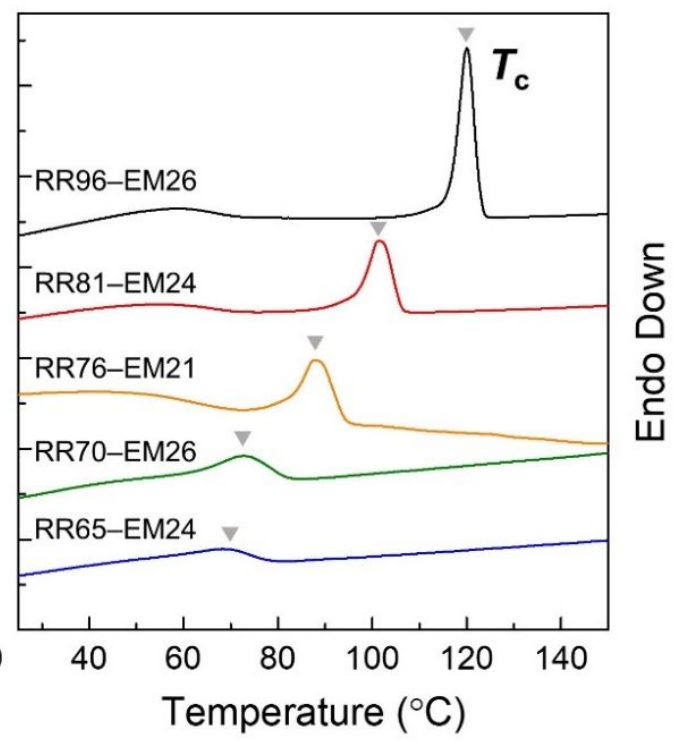

Figure S4. DSC second (a) heating and (b) cooling thermograms of cylinder forming P3DDT$b$-PEMA copolymers with different RR.

$2^{\text {nd }}$ Heating Cycle

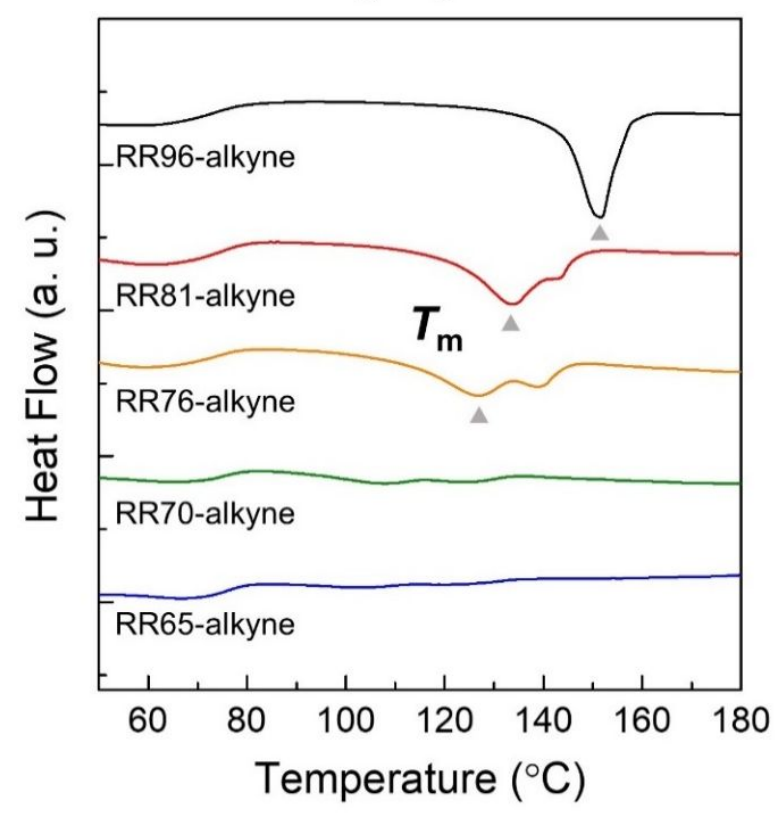

Figure S5. DSC second heating thermograms of P3DDT-alkynes with different RR. 
Table S1. Summary of thermal properties of polymers used in this study.

\begin{tabular}{ccccc}
\hline Polymer & $T_{\mathrm{m}}\left[{ }^{\circ} \mathrm{C}\right]$ & $T_{\mathrm{c}}\left[{ }^{\circ} \mathrm{C}\right]$ & $\Delta H_{\mathrm{m}}\left[\mathrm{J} \mathrm{g}^{-1}\right]$ & $\mathrm{D}_{\mathrm{c}, \text { P3DDT }}[\%]^{\mathrm{a}}$ \\
\hline RR96-alkyne & 151.6 & 114.3 & 9.9 & 19.0 \\
RR96-EM26 & 158.1 & 120.1 & 8.4 & 21.8 \\
RR96-EM50 & 157.5 & 114.3 & 6.7 & 25.6 \\
\hline RR81-alkyne & 133.9 & 97.8 & 4.9 & 9.5 \\
RR81-EM24 & 139.5 & 101.5 & 4.8 & 12.2 \\
RR81-EM49 & 136.7 & 96.8 & 4.2 & 15.9 \\
\hline RR76-alkyne & 126.9 & 89.4 & 3.6 & 6.8 \\
RR76-EM21 & 129.6 & 88.1 & 3.0 & 7.2 \\
RR76-EM44 & 131.5 & 91.5 & 2.5 & 8.5 \\
\hline RR70-alkyne & - & 68.6 & - & - \\
RR70-EM26 & - & 73.0 & - & - \\
RR70-EM48 & - & 73.1 & - & - \\
\hline RR65-alkyne & - & 61.9 & - & - \\
RR65-EM24 & - & 69.9 & - & - \\
RR65-EM47 & - & 68.2 & & - \\
\hline
\end{tabular}

aThe $\mathrm{D}_{\mathrm{c}, \mathrm{P3DDT}}$ values of BCPs were calculated by comparing their melting enthalpy $\left(\Delta H_{\mathrm{m}}\right)$ with the melting enthalpy of an ideal P3DDT crystallite $\left(\Delta H_{\mathrm{m}}{ }^{0}=52 \mathrm{~J} \mathrm{~g}^{-1}\right)^{3}$, considering only the weight of the P3DDT component.

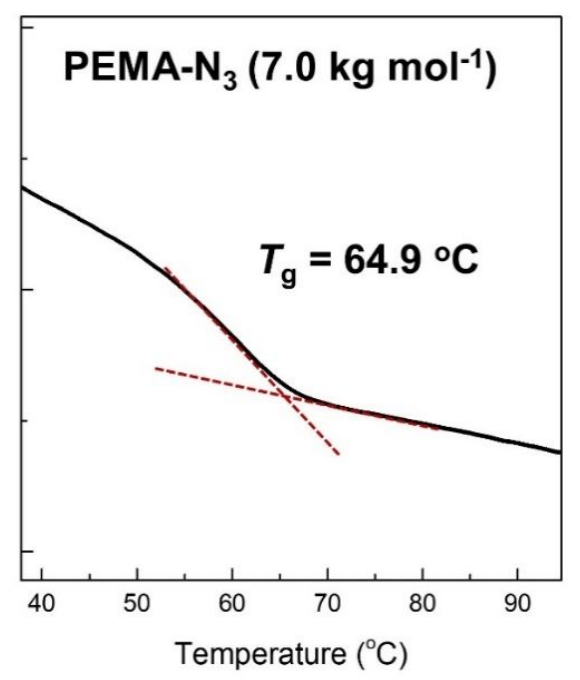

Figure S6. Measurement of $T_{\mathrm{g}}$ of PEMA-N $3\left(M_{\mathrm{n}}=7.0 \mathrm{~kg} \mathrm{~mol}^{-1}\right)$ using DSC second heating thermogram. 

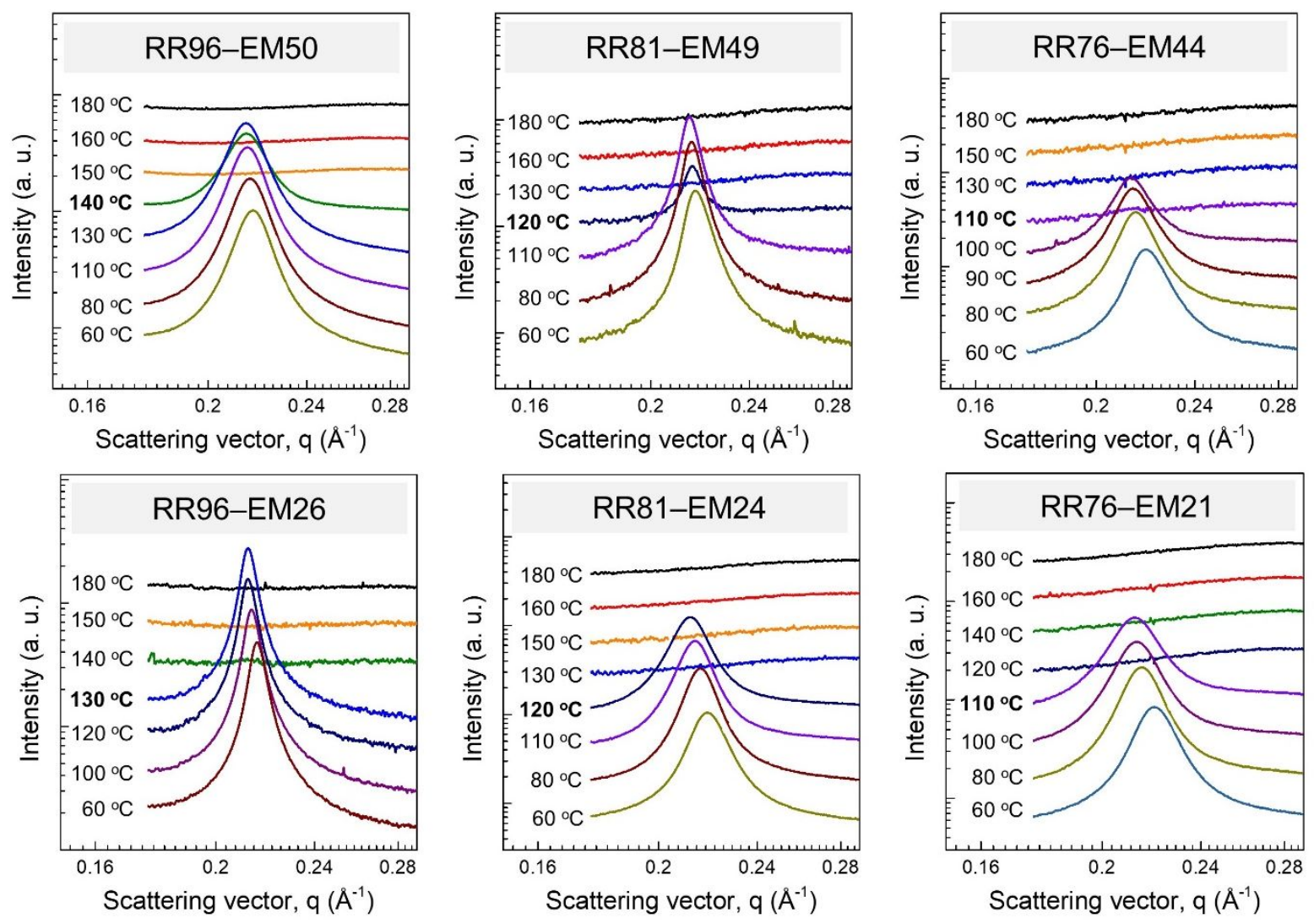

Figure S7. Temperature-dependent change in intensity of primary WAXS peak of P3DDT- $b$ PEMA with RR of 96,81 and $76 \%$. 

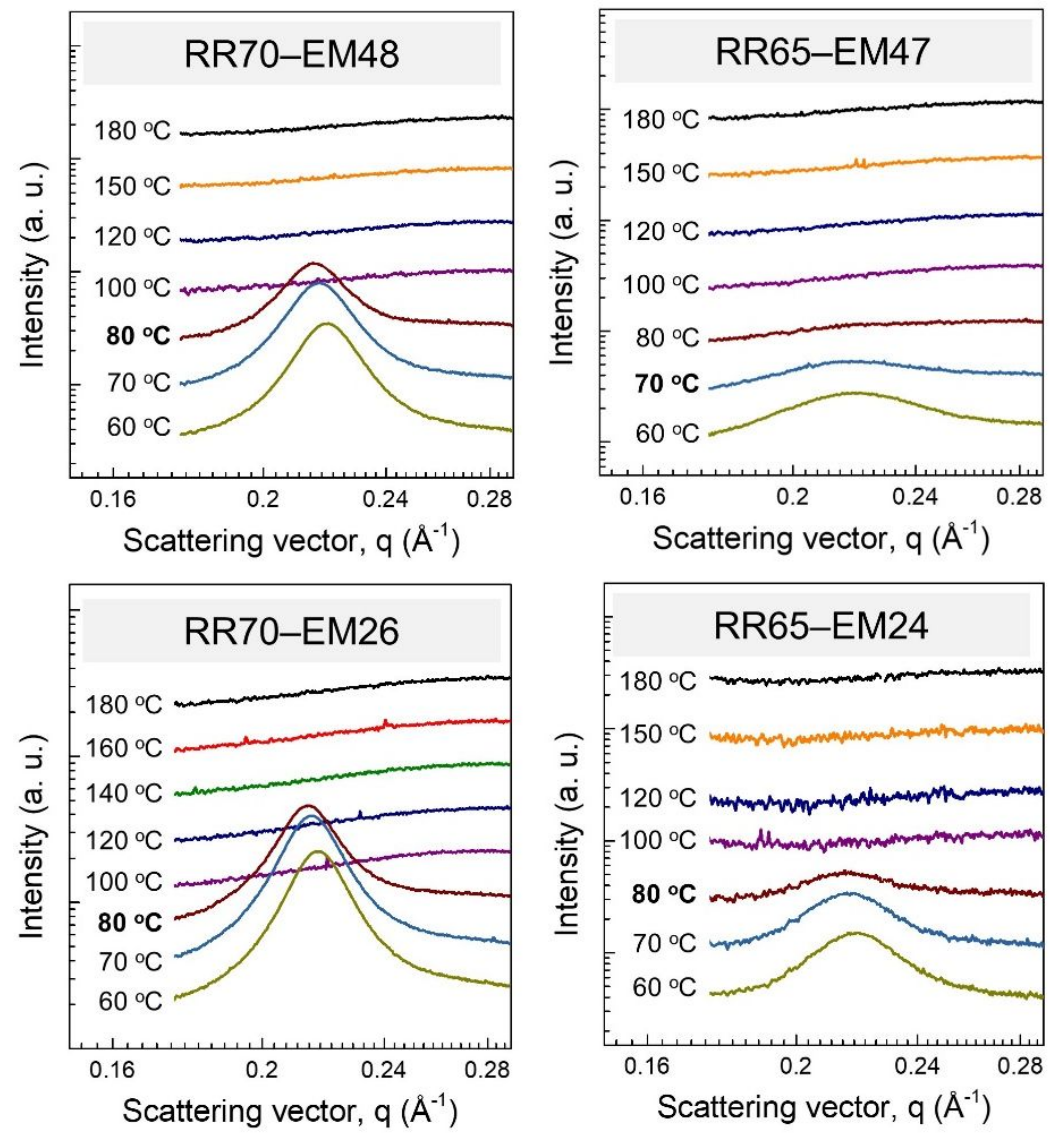

Figure S8. Temperature-dependent change in intensity of primary WAXS peak of P3DDT- $b$ PEMA with RR of 70 and $65 \%$. 

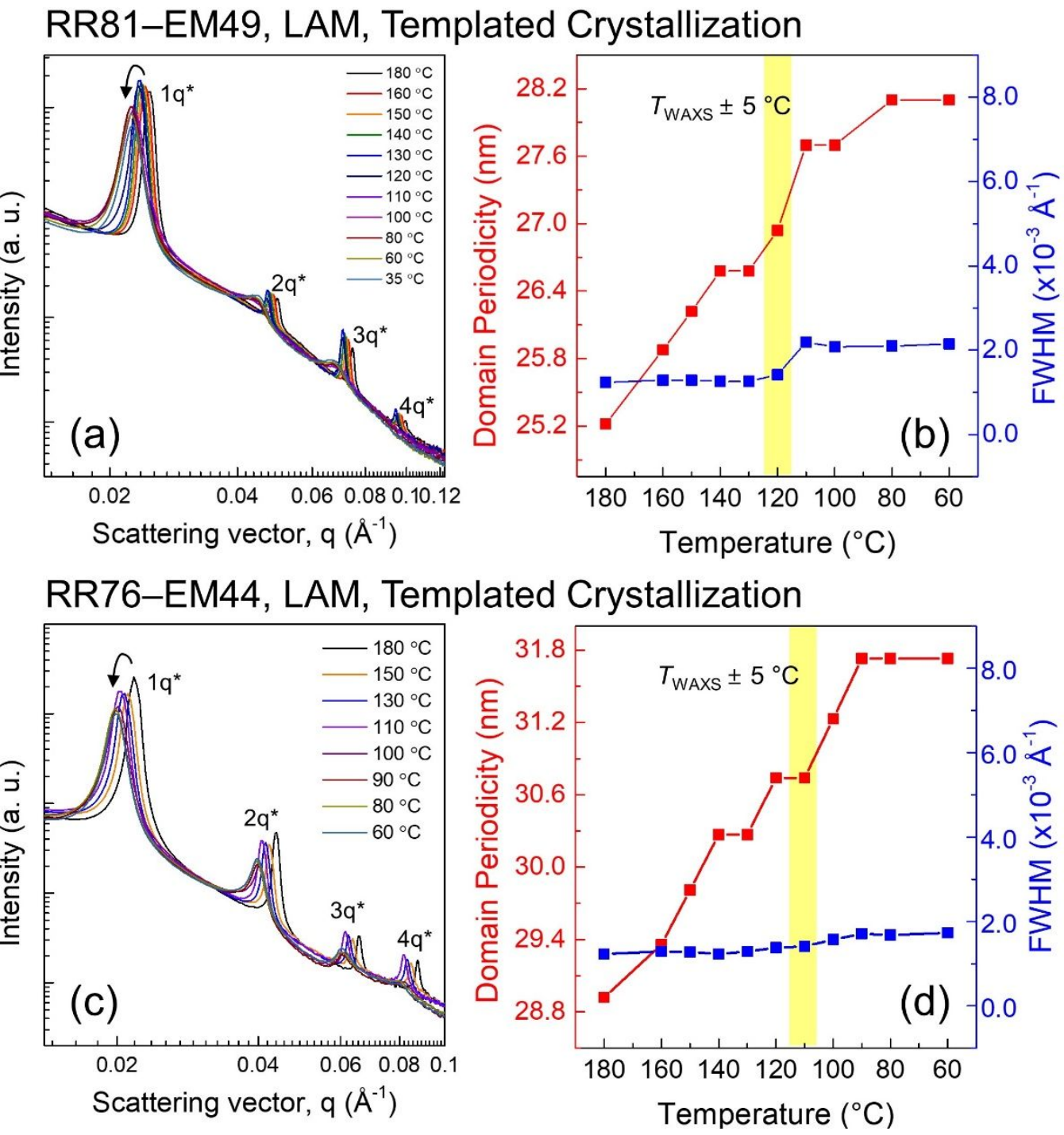

Figure S9. In situ SAXS profiles of (a) RR81-EM49 and (c) RR76-EM44. Plots of domain periodicity of SAXS structure and FWHM of primary SAXS peak for (b) RR81-EM49 and (d) RR76-EM44 upon cooling from 180 to $60{ }^{\circ} \mathrm{C}$. 
RR65-EM47, LAM, Confined Crystallization
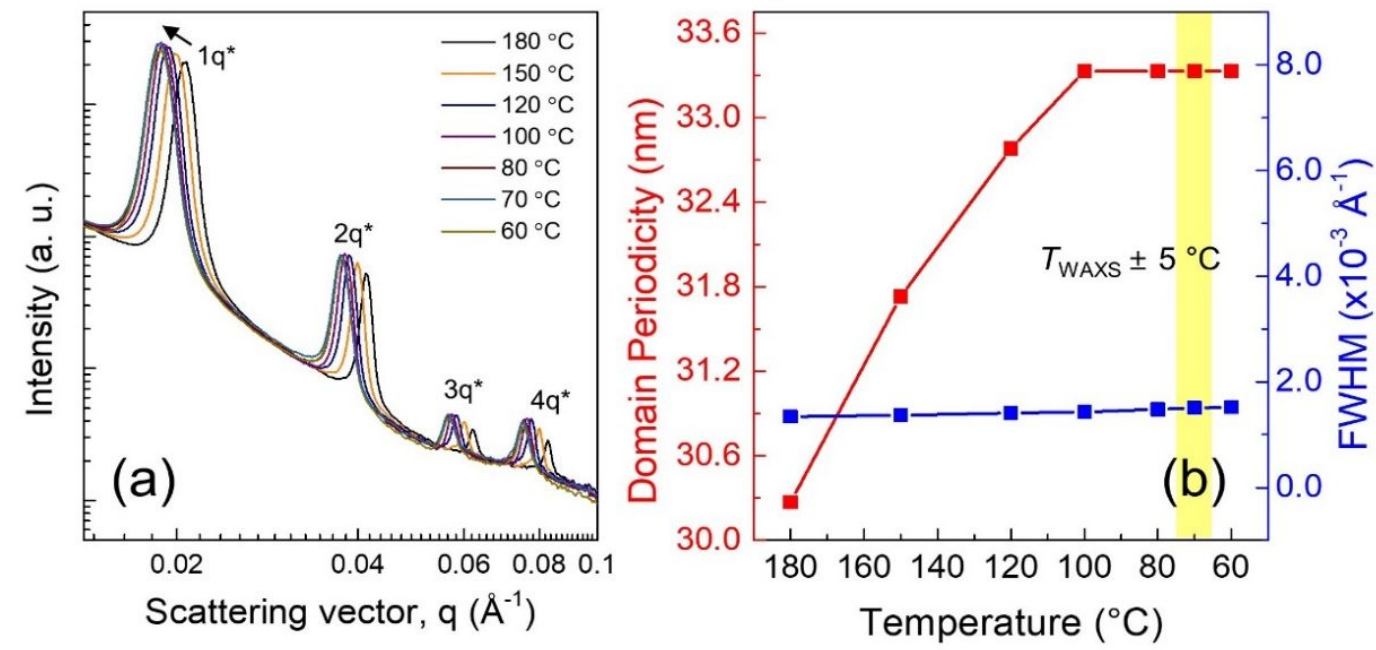

Figure S10. In situ SAXS profiles of (a) RR65-EM47. Plots of domain periodicity of SAXS structure and FWHM of primary SAXS peak for (b) RR65-EM47 upon cooling from 180 to $60{ }^{\circ} \mathrm{C}$. 
RR81-EM24, HPC, Breakout Crystallization

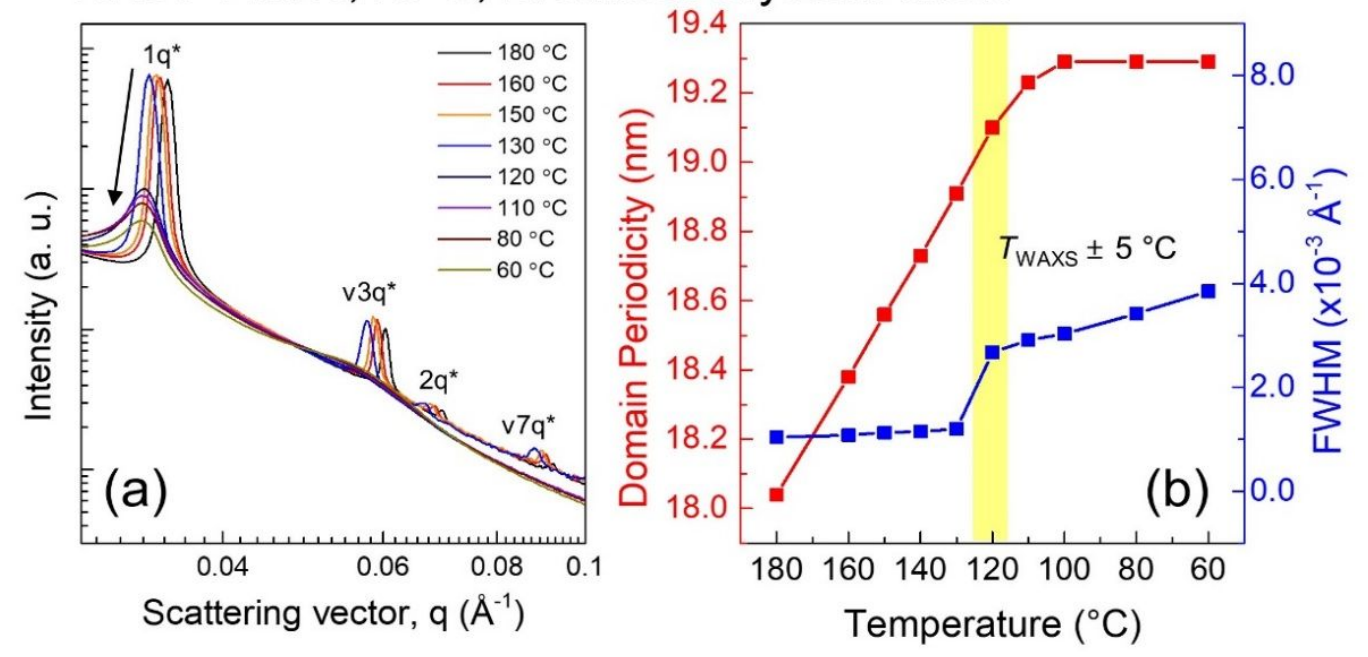

RR76-EM21, HPC, Breakout Crystallization
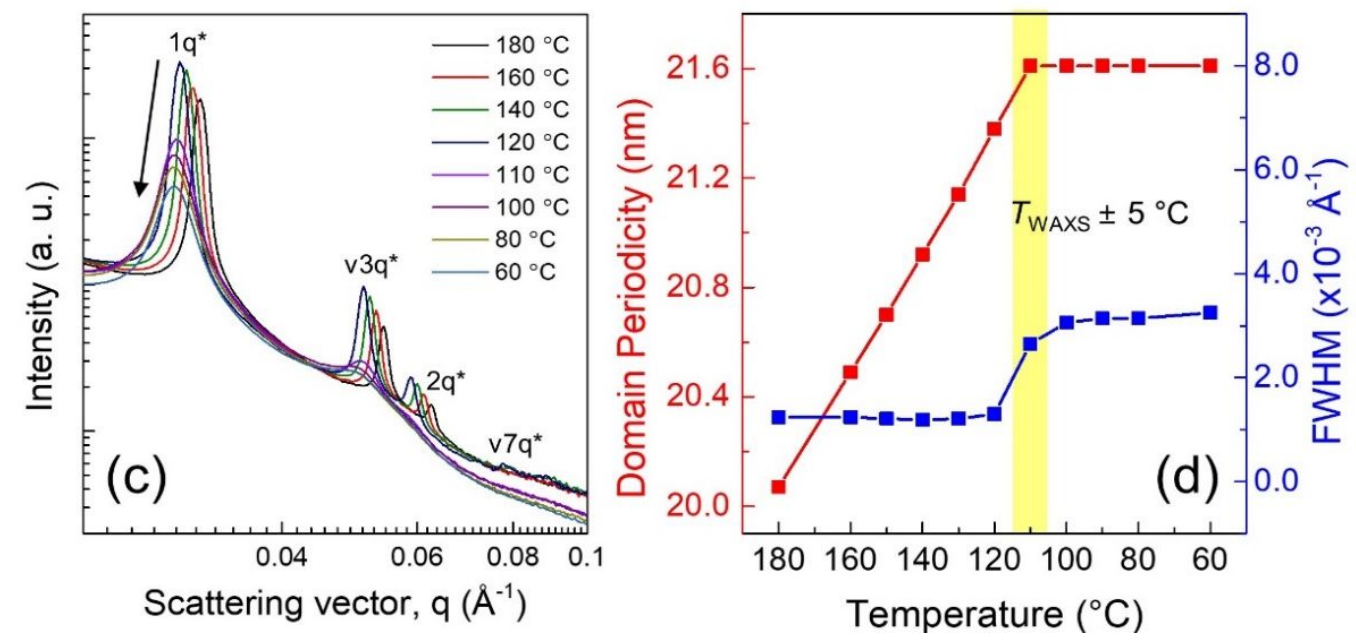

Figure S11. In situ SAXS profiles of (a) RR81-EM24 and (c) RR76-EM21. Plots of domain periodicity of SAXS structure and FWHM of primary SAXS peak for (b) RR81-EM24 and (d) RR76-EM21 upon cooling from 180 to $60{ }^{\circ} \mathrm{C}$. 
RR65-EM24, HPC, Templated Crystallization

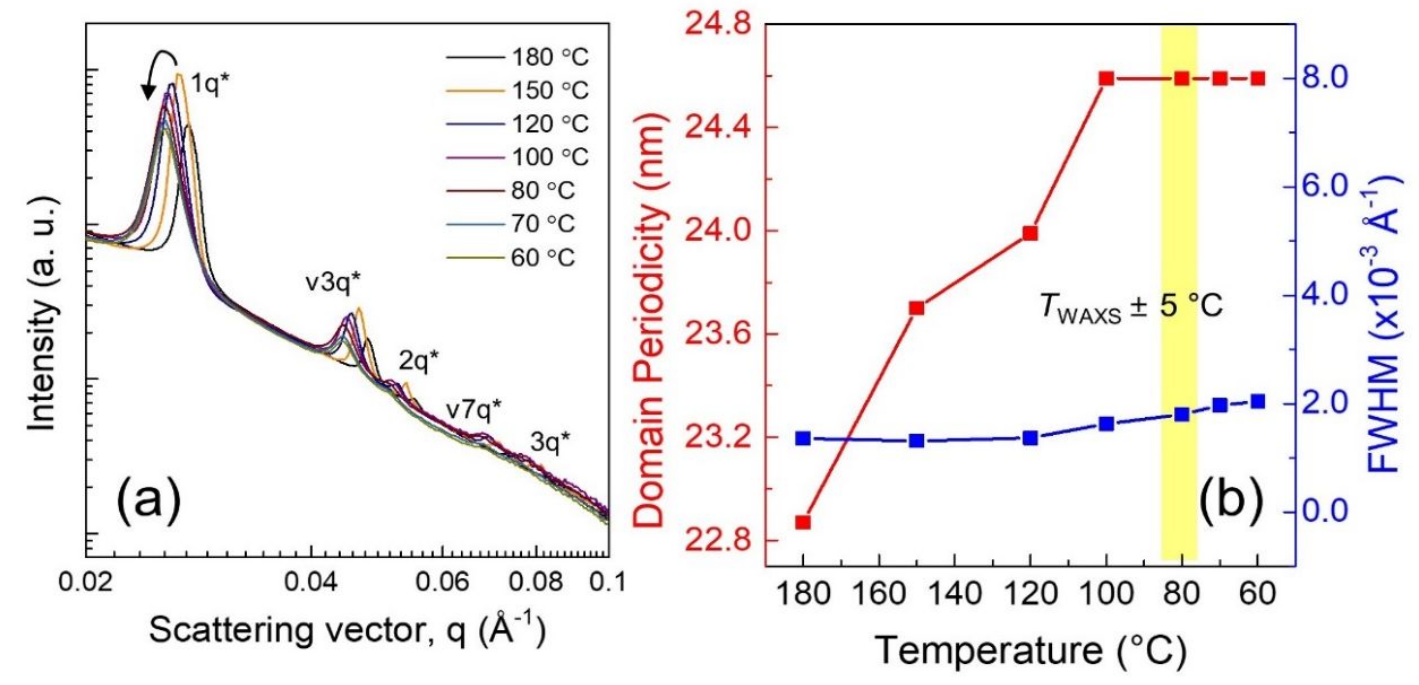

Figure S12. In situ SAXS profiles of (a) RR65-EM24. Plots of domain periodicity of SAXS structure and FWHM of primary SAXS peak for (b) RR65-EM24 upon cooling from 180 to $60{ }^{\circ} \mathrm{C}$. 
(a) RR70-EM48
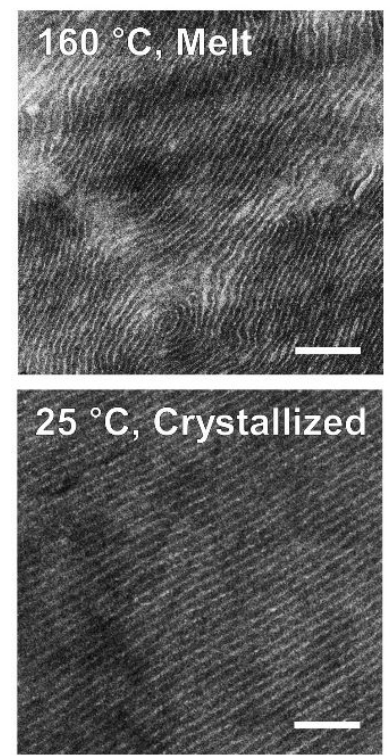

LAM, Confined (b) RR76-EM44
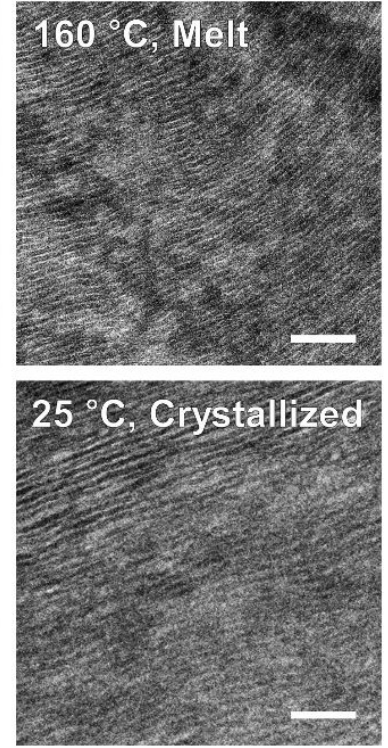

LAM, Templated (c) RR81-EM49
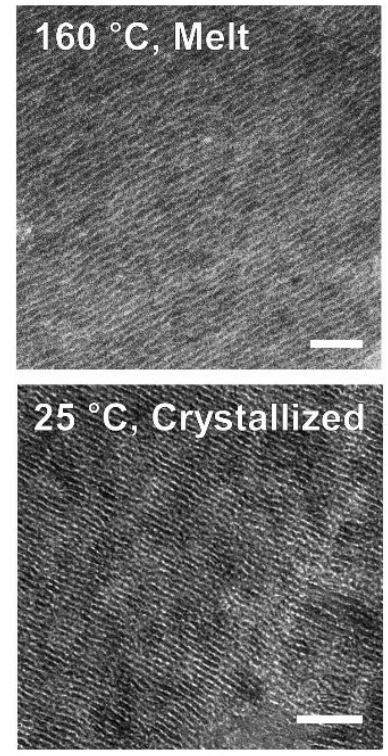

LAM, Templated (d) RR96-EM50
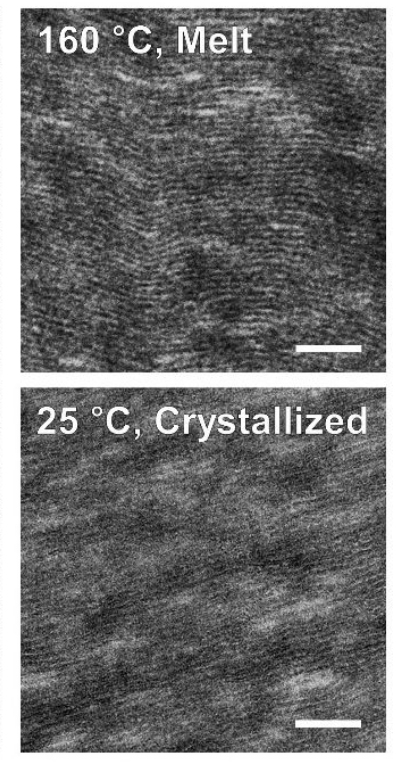

LAM, Templated

Figure S13. Cross-sectional TEM images of lamellar forming BCPs: (a) RR70-E48; (b) RR76-EM44; (c) RR81-EM49; (d) RR96-EM50. P3DDT domains were selectively stained dark by exposure to $\mathrm{RuO}_{4}$ vapor. The scale bars are $200 \mathrm{~nm}$.
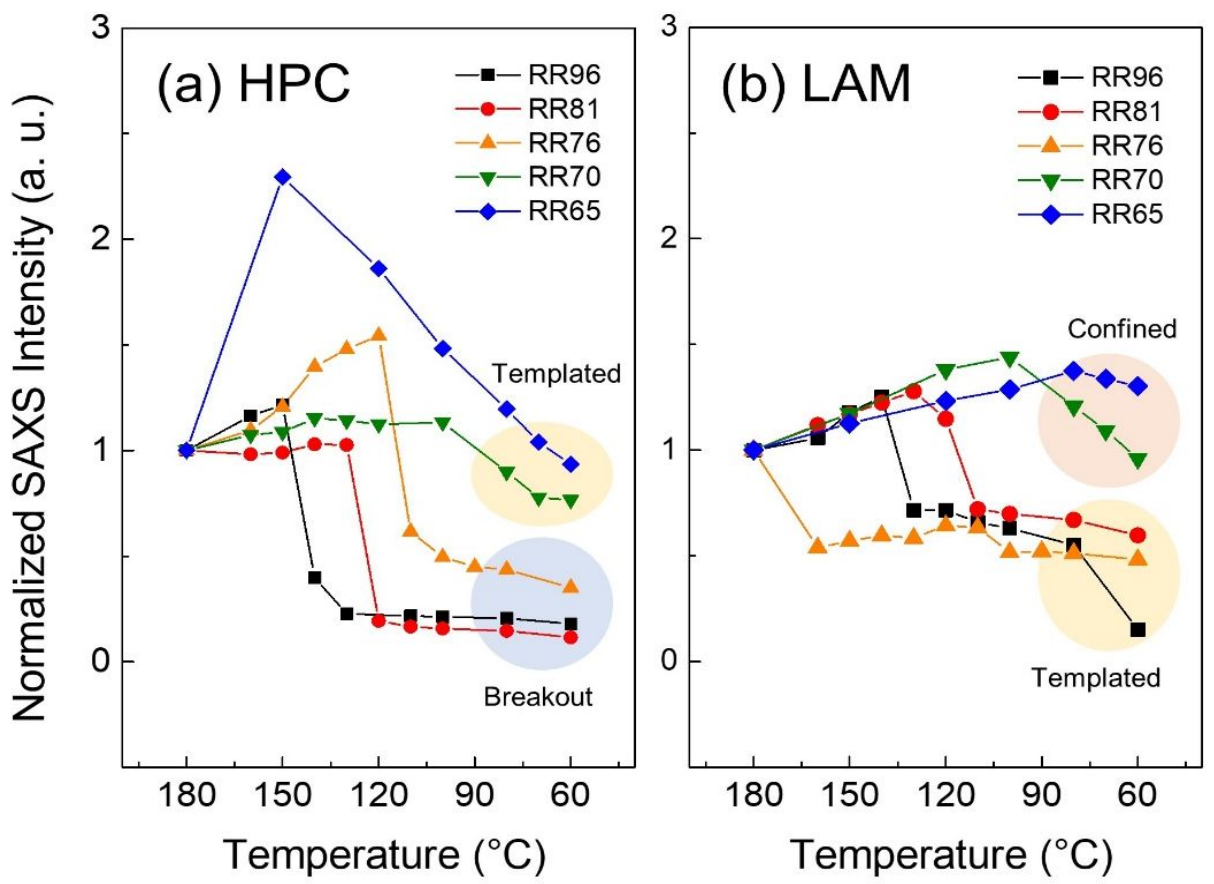

Figure S14. Normalized intensity of primary SAXS peak of (a) HPC and (b) LAM forming P3DDT- $b$-PEMA copolymers with different RR as a function of temperature. 


\section{References}

[1] Singh, D. P.; Kalachandra, S.; Turner, D. T., Glass-Transition of Polymers Made from Slurries of Poly(Ethyl Methacrylate) and Methyl-Methacrylate. J. Polym. Sci. B Polym. Phys. 1988, 26 (8), 1795-1799.

[2] Tashiro, K.; Ono, K.; Minagawa, Y.; Kobayashi, M.; Kawai, T.; Yoshino, K., Structure and Thermochromic Solid-State Phase-Transition of Poly(3-Alkylthiophene). J. Polym. Sci. B Polym. Phys. 1991, 29 (10), 1223-1233.

[3] Malik, S.; Nandi, A. K., Crystallization Mechanism of Regioregular Poly(3Alkylthiophene)s. J. Polym. Sci. B Polym. Phys. 2002, 40 (18), 2073-2085. 